ISSN 1112-9867

http://www.jfas.info

\title{
SILICA COATED IONIC LIQUID TEMPLATED MESOPOROUS SILICA NANOPARTICLES
}

\author{
E. D. M. Isa ${ }^{1}$, M. B. A. Rahman ${ }^{1,2}$ and H. Ahmad ${ }^{1,2, *}$ \\ ${ }^{1}$ Deparment of Chemistry, Faculty Science, Universiti Putra Malaysia, 43400 Serdang, \\ Selangor, Malaysia \\ ${ }^{2}$ Enzyme and Microbial Technology Research Centre (EMTech), Universiti Putra Malaysia, \\ 43400 Serdang, Selangor, Malaysia
}

Published online: 10 November 2017

\begin{abstract}
A series of long chain pyridinium based ionic liquids 1-tetradecylpyridinium bromide, 1-hexadecylpyridinium bromide and 1-octadecylpyridinium bromide were used as templates to prepare silica coated mesoporous silica nanoparticles via condensation method under basic condition. The effects of alkyl chain length on particles morphology were primarily studied. The materials were characterized by X-ray diffraction, transmission electron microscopy and nitrogen adsorption-desorption. Analysis indicates that the particles obtained were in spherical shape with decreasing size as the alkyl chain length of ionic liquid increases. The materials also show increase of BET surface value as the alkyl chain length increases from the range 19 $\mathrm{m}^{2} / \mathrm{g}$ to $23 \mathrm{~m}^{2} / \mathrm{g}$.
\end{abstract}

Keywords: mesoporous silica; ionic liquid; pyridinium; nanoparticles.

Author Correspondence, e-mail: haslina_ahmad@upm.edu.my

doi: http://dx.doi.org/10.4314/jfas.v9i6s.16 


\section{INTRODUCTION}

Porous materials have become more important due to its properties and according to IUPAC classification, materials with pores with diameter less than $2 \mathrm{~nm}$, between 2 and $50 \mathrm{~nm}$ and more than $50 \mathrm{~nm}$ are defined as micropores, mesoporous and macroporous respectively [1-2]. Among all of these porosity types, the focus falls on mesoporous material ever since the reported findings by Mobil Oil Research regarding a new family of ordered mesoporous silica materials which was named M41S in the year 1992 [1,3]. The rise of the field nanotechnology helps in development of mesoporous materials to mesoporous nanoparticles. One of nanoparticles develop is mesoporous silica nanoparticles (MSNs). This material is favourable due to the easy tailoring ability of this material which can suit many potential applications such as catalyst, absorbent, separation and biomedical application [2, 4-5]. In the formation of MSNs, the synthesis uses surfactant's micelle as structure directing agent to form mesostructure. The surfactant's micelle which can be refer as the template is then removed either via acid-assisted-solvent extraction or calcination and the space occupy by it form channels in the material [6]. Currently, the most commonly used template are anionic surfactants such as quaternary ammonium salts and polymers [2], and this has given opportunity to other materials to be a template in MSNs synthesis.

Ionic liquids (Ils) can be defined as salts with melting point below the boiling point of water [7]. The first ionic liquid was first reported in the year 1914 with melting point of $12{ }^{\circ} \mathrm{C}[6,8]$. Ils are well-known in the field of green chemistry due to their properties such as essentially zero vapour pressure, high thermal stability and nonflammibility which minimize air pollution compared to organic solvents [2,9-10]. It consists of anions and cations which is similar to the core component anionic surfactant used in MSNs synthesis. Therefore, there is potential in utilizing Ils as templates.

In these recent decades, several researchers have reported the realization of Ils as template in mesoporous materials synthesis. Imidazolium based Ils are of particular interest especially the long chain as it has the tendency to self-assemble which is preferable in development of ordered mesoporous materials [11]. In [12] reported the usage of a series of 1-alkyl-3-methylimidazolium chloride $\left(\mathrm{C}_{\mathrm{n}} \mathrm{MimCl}\right.$ where $\mathrm{n}=10,14,16$ and 18$)$ in the preparation of highly ordered lamellar silica via nanocasting technique and it show microporosity with ca. 
$1.2 \mathrm{~nm}-1.5 \mathrm{~nm}$. In another work, two types of mesopore structures which are the MCM-41 and MCM-48 type were generated by using 1-hexadecyl-3-methylimidazolium chloride as template via hydrothermal synthesis [11]. Although most works focus on long chain Ils, in $[2,12]$ reported synthesis of mesoporous silica using 1-butyl-3-methylimidazolium tetrafluoroborate $\left(\mathrm{C}_{4} \mathrm{MimBF}_{4}\right)$ through new mechanism proposed known as hydrogen bond-co- $\pi$ - $\pi$-stack mechanism. Despite all these advancements, there were no report on the usage of Ils in the synthesis of silica coated MSNs.

Herein, we present a new synthesis approach to prepare silica coated MSNs (SMSNs) by using pyridinium-based Ils as template. In addition, the effect of Ils chain length on silica coated MSNs were also investigated.

\section{MATERIALS AND METHODS}

\subsection{Materials and Reagents}

All chemicals used in the experiments were of analytical grade and used without further purification.

\subsection{Syntheses}

\subsubsection{Synthesis of PyridiniumIls}

The pyridiniumIls were prepared according to [13-14]with some modifications. 1-tetradecylpyridinium bromide $\left(\mathrm{C}_{14} \mathrm{PyBr}\right)$, 1-hexadecylpyridinium bromide $\left(\mathrm{C}_{16} \mathrm{PyBr}\right)$ and 1-octadecylpyridinium bromide $\left(\mathrm{C}_{18} \mathrm{PyBr}\right)$ were obtained by reacting pyridine $(33 \mathrm{mmol})$ with 1-bromotetradecane $(40 \mathrm{mmol}), 1$-bromohexadecane $(40 \mathrm{mmol})$ and 1-bromooctadecane $(40$ mmol) respectively in ethanol $(10 \mathrm{~mL})$, at $110{ }^{\circ} \mathrm{C}$ under reflux condition for 24 hours. The products obtained were purified by dissolving it in minimum amount of acetonitrile and precipitated using diethyl ether. The solids obtained were further dried under desiccants to remove excess solvent. $\mathrm{C}_{14} \mathrm{PyBr} \mathrm{H}^{1} \mathrm{NMR}\left(\mathrm{DMSO} d_{6}\right): \delta 0.78-0.81(\mathrm{t}, J=6.85 \mathrm{~Hz}, 3 \mathrm{H}), 1.22$ $-1.23(\mathrm{~m}, 22 \mathrm{H}), 1.85-1.88(\mathrm{~m}, 2 \mathrm{H}), 4.57-4.60(\mathrm{t}, J=8.00 \mathrm{~Hz}, 2 \mathrm{H}), 8.11-8.14(\mathrm{~m}, 2 \mathrm{H})$, $8.56-8.59$ (t, $J=8.00 \mathrm{~Hz}, 1 \mathrm{H}), 9.11-9.12(\mathrm{~m}, 2 \mathrm{H}) . \mathrm{C}_{16} \mathrm{PyBr} \mathrm{H}{ }^{1} \mathrm{NMR}\left(\mathrm{DMSO} d_{6}\right): \delta 0.78-$ $0.81(\mathrm{t}, J=6.86 \mathrm{~Hz}, 3 \mathrm{H}), 1.18-1.22(\mathrm{~m}, 26 \mathrm{H}), 1.85-1.88(\mathrm{~m}, 2 \mathrm{H}), 4.57-4.60(\mathrm{t}, J=8.05$ $\mathrm{Hz}, 2 \mathrm{H}), 8.11-8.14(\mathrm{~m}, 2 \mathrm{H}), 8.56-8.59(\mathrm{~m}, 1 \mathrm{H}), 9.11-9.12(\mathrm{~m}, 2 \mathrm{H}) . \mathrm{C}_{18} \mathrm{PyBr} \mathrm{H}^{1} \mathrm{NMR}$ $\left(\mathrm{DMSO} d_{6}\right): \delta 0.78-0.81(\mathrm{t}, J=6.86 \mathrm{~Hz}, 3 \mathrm{H}), 1.19-1.23(\mathrm{~m}, 30 \mathrm{H}), 1.85-1.88(\mathrm{~m}, 2 \mathrm{H})$, 
$4.57-4.60(\mathrm{t}, J=8.05 \mathrm{~Hz}, 2 \mathrm{H}), 8.11-8.14(\mathrm{~m}, 2 \mathrm{H}), 8.56-8.59(\mathrm{~m}, 1 \mathrm{H}), 9.11-9.12(\mathrm{~m}$, $2 \mathrm{H})$.

\subsubsection{Synthesis of SMSNs}

The synthesis method was adapted and modified from [5,15]. Ils $(0.05 \mathrm{~g})$, triethanolamine $(0.06 \mathrm{~g})$, sodium acetate trihydrate $(0.12 \mathrm{~g})$ were dissolved in deionized water $(20 \mathrm{~mL})$. The mixture was stirred at $400 \mathrm{rpm}$ and was maintained at $95{ }^{\circ} \mathrm{C}$ for 1 hour. Tetraethylorthosilicate $(1.5 \mathrm{~mL})$ was added dropwise with the rate of $1 \mathrm{~mL} / \mathrm{min}$. After continuous stirring for 1 hour at $95{ }^{\circ} \mathrm{C}$, the mixtures were cooled to room temperature. The products were collected via centrifugation at $6000 \mathrm{rpm}$ for 15 minutes and washed with ethanol several times to remove excess reactants. The final products were dried in the oven at $55{ }^{\circ} \mathrm{C}$ for 24 hours. The products were named C14-SMSNs, C16-SMSNs and C18-SMSNs according to Ils $\mathrm{C}_{14} \mathrm{PyBr}, \mathrm{C}_{16} \mathrm{PyBr}$ and $\mathrm{C}_{18} \mathrm{PyBr}$ respectively.

\subsection{Characterization and Instrumentations}

The Nuclear Magnetic Resonance (NMR) spectra for ${ }^{1} \mathrm{H}$ were recorded on JEOL EXC500 FT. Deuterated dimethyl sulfoxide (DMSO) was used as solvents for all Ils. Powder X-ray diffractogram were collected on Brucker D8 Discover using $\mathrm{Cu} \mathrm{K} \alpha$ radiation over a $2 \theta$ range of $1-9^{\circ}$ at a scan rate of $1 \% \mathrm{~min}$. Transmission electron micrographs (TEM) were recorded on Tecnai G2 F20 operating at 200kV. Samples were dispersed in ethanol under ultrasonication for 20 minutes. One droplet of suspension was applied to a 400-mesh carbon-coated copper grid and dried in air. BET surface area, average pore volume and average pore diameter of the SMSNs were measured by physisorption of $\mathrm{N}_{2}$ at $77 \mathrm{~K}$ over a Micromeritics ASAP 2020. Before measurement, the samples were degassed at $200{ }^{\circ} \mathrm{C}$ for 6 hours to remove moisture and adsorbed gas.

\section{RESULTS AND DISCUSSION}

Target pyridiniumIls were prepared according to the standardized method. In this method, ethanol was used as solvent to reduce the viscosity of the solution during the reaction. Desired pyridiniumIls were formed through alkylation reaction between pyridine and bromoalkaneswith different alkyl chain length (Scheme 1)[14] as presented in Fig. 1. 


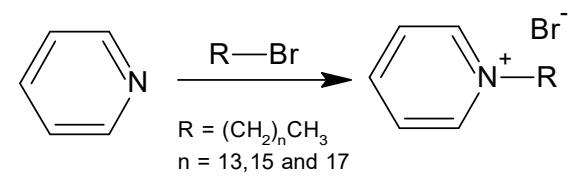

Fig.1.Scheme 1: Synthesis of pyridiniumIls

SMSNs were prepared through modified method of previous research [5,15]. The target materials were obtained through condensation reaction with tetraethylorthosilicate as silica source and pyridiniumIls as template under basic condition. In this reaction, both triethanolamine and sodium acetate trihydrate serve as catalyst. Furthermore, triethanolamine serve a few other purposes as well such as silicate species complexing agent and encapsulator which causes the particles produce to be in spherical shape [16]. SMSNs were then characterized using XRD and the diffractogram of the three samples are shown in Fig. 2. It exhibit no peaks at low angle which show that all the SMSNs lack of specific ordering and the materials obtained were amorphous[2,17].

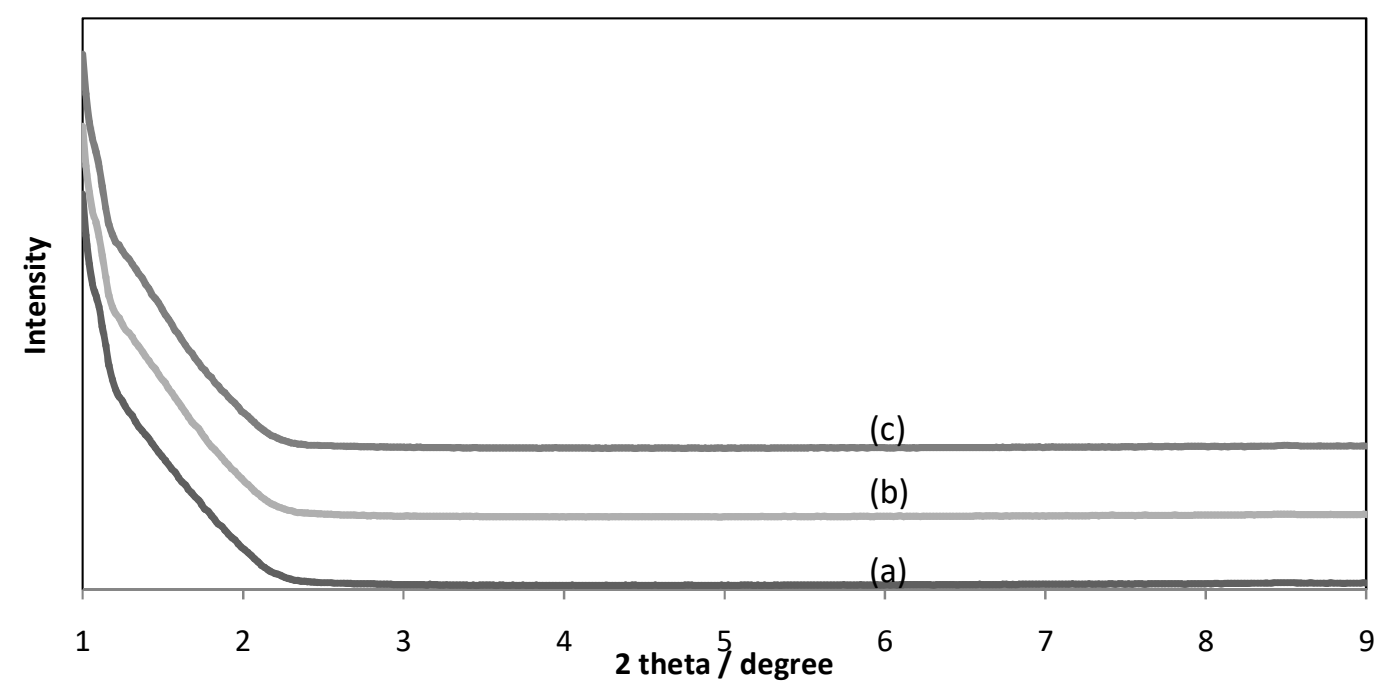

Fig.2. XRD diffractogram of (a) C14-SMSNs, (b) C16-SMSNs and (c) C18-SMSNs

TEM was employed to study the morphological and the internal structure of the particles. The micrograph show that all the synthesized SMSNs obtained were in spherical shape. It also found that porosity form are in uniform size with no large pores. The pores are in wormlike shape and aligned towards the centre of the particles. It is noted from Fig. 3, the presence of non-porous silica layer surrounding the particles. 


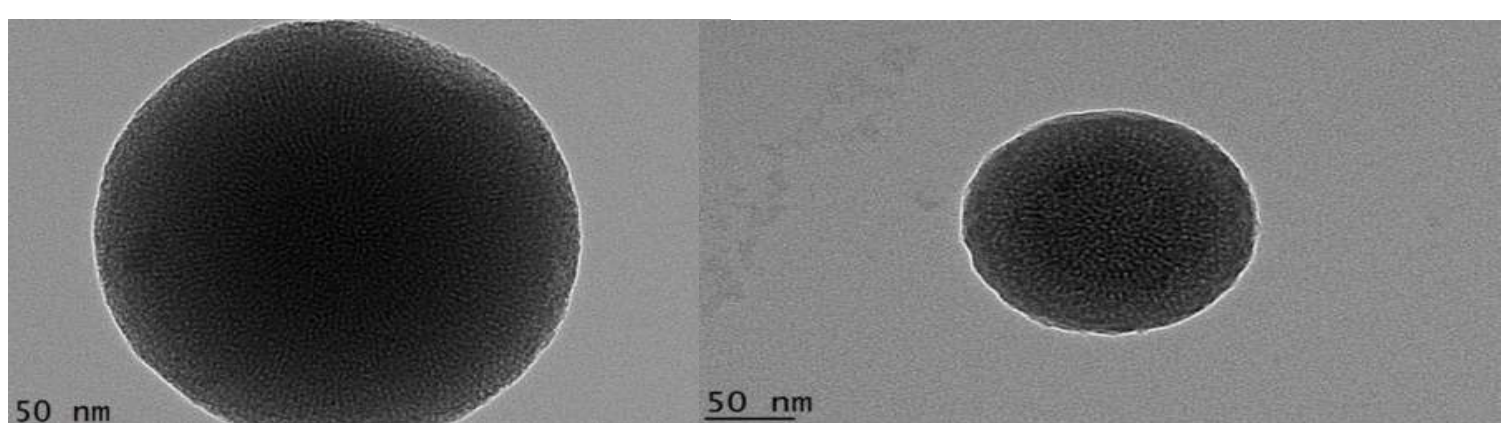

(a)

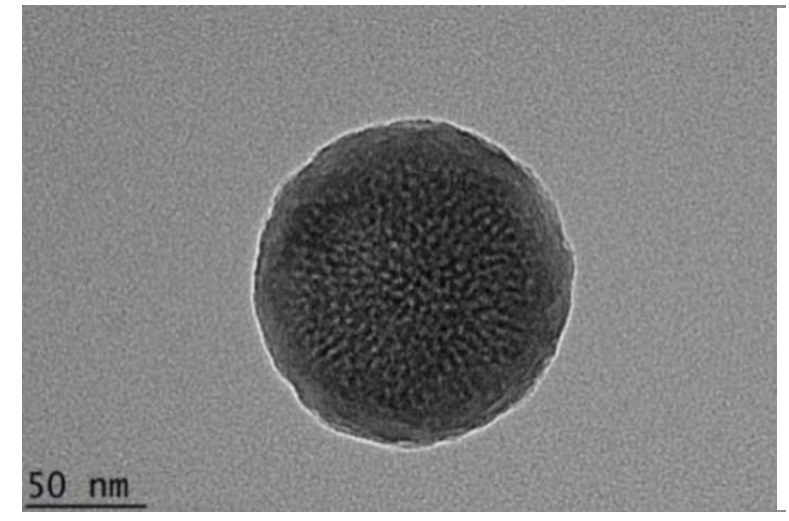

(c) (b)

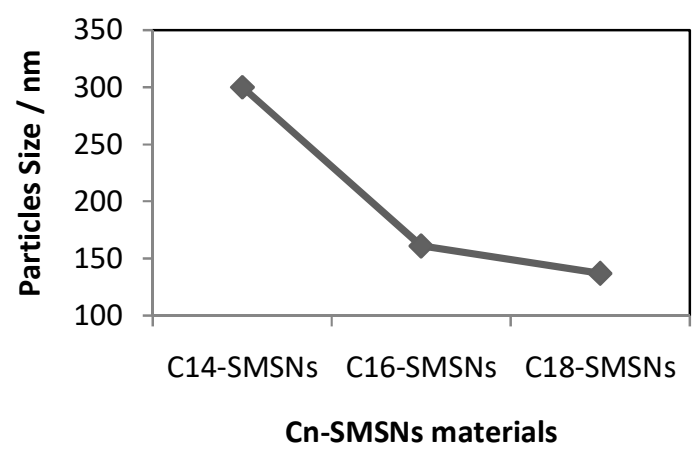

(d)

Fig.3.TEM of Cn-SMSNs materials (a) C14-SMSNs, (b) C16-SMSNs, (c) C18-SMSNs and (d) size trend of Cn-SMSNs materials

The formation of this silica layer was due to excess of silica source as its concentration is higher than the template concentration [18]. The particles size of the SMSNs can also been determined from the TEM micrograph which are $300 \mathrm{~nm}, 161 \mathrm{~nm}$ and $137 \mathrm{~nm}$ for C14-SMSNs, C16-SMSNs and C18-SMSNs respectively. It can be deduced that as the alkyl chain length of pyridiniumIls increase, the particles size decreases. The reason for this observation was due to the differences of critical micelle concentration (CMC) between different alkyl chain lengths of pyridiniumIls. Longer alkyl chain length has lower CMC value thus in the solution more nuclei form which lead to the formation of the smaller particles of SMSNs[19-20].

Fig.4 shows the nitrogen sorption data of samples C14-SMSNs, C16-SMSNs and C18-SMSNS and from the figure, all the samples exhibit type II isotherm. According to IUPAC classification for silicate mesoporous materials, type II isotherm represent non-porous or macroporous materials [21]. However, it can be concluded that the materials obtained were non-porous which is agreeable to the TEM images whereby the presence of non-porous silica layer present surrounding the particles. High volume adsorped at high relative pressure might 
be due to the interparticle spaces.

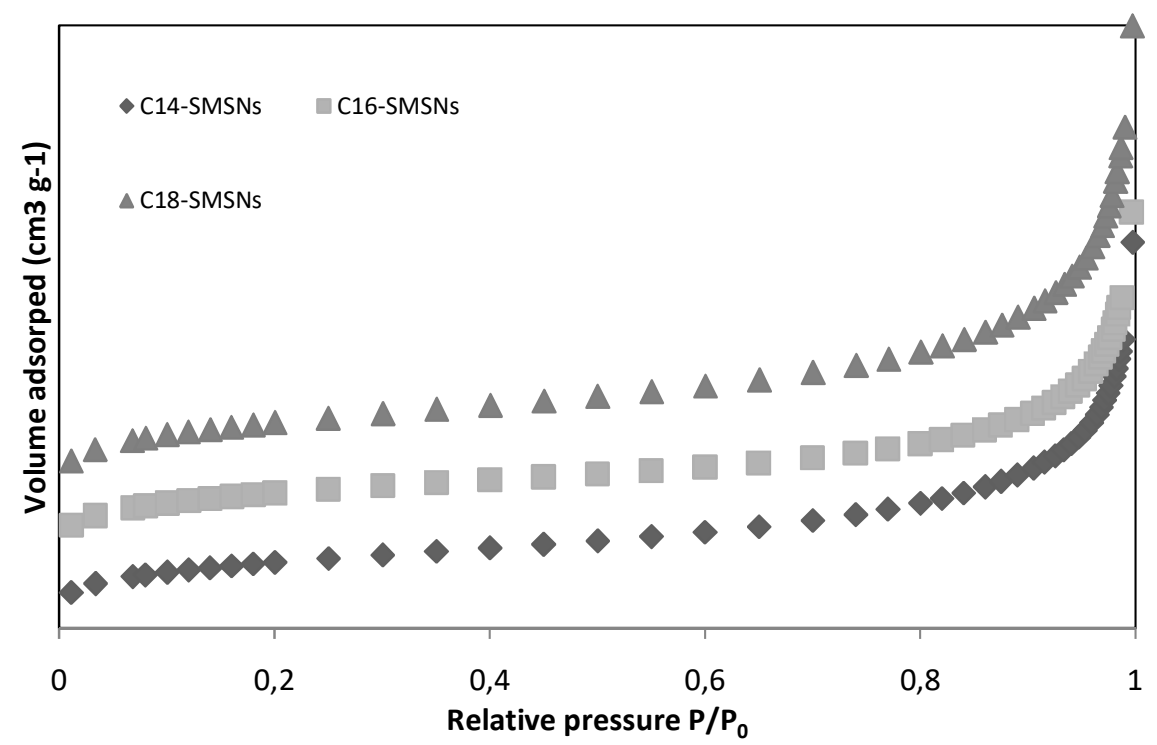

Fig.4. Nitrogen adsorption-desorption isotherm of samples C14-SMSNs, C16-SMSNs and

\section{C18-SMSNs}

Table 1 tabulated the rate of sorption analysis, BET surface area, pore volume and BJH average pore diameter. As the alkyl chain length of pyridiniumIls increase, the BET surface area value increase. This is concurrent with the particles size whereby surface area increase with the decrease of particle size. The pore volumes for all the SMSNs were very low, which is below $0.05 \mathrm{~cm}^{3} / \mathrm{g}$. Typical mesoporous materials have high surface area and pore volume value. Low surface area and pore volume value indicate that the materials synthesised were not mesoporous and this further proves the presence of non-porous silica layer. The BJH average pore diameter value obtained were closed to $100 \AA$ which is relatively high and this was due to interparticle spaces.

Table 1. Sample and nitrogen sorption data

\begin{tabular}{cccc}
\hline Sample & $\begin{array}{c}\text { BET } \\
\text { Surface Area }\left(\mathbf{m}^{\mathbf{2}} / \mathbf{g}\right)\end{array}$ & $\begin{array}{c}\text { Pore Volume } \\
\left(\mathbf{c m}^{\mathbf{3}} \mathbf{g}\right)\end{array}$ & $\begin{array}{c}\text { BJH Average Pore } \\
\text { Diameter }(\mathbf{\AA})\end{array}$ \\
\hline C14-SMSNs & 19.91 & 0.0495 & 99.44 \\
C16-SMSNs & 22.43 & 0.0457 & 81.43 \\
C18-SMSNs & 23.64 & 0.0618 & 97.08 \\
\hline
\end{tabular}




\section{CONCLUSION}

In summary, silica coated mesoporous silica nanoparticles have been successfully synthesised.

Based on the experimental result, SMSNs obtained were in spherical shape and the particles size decrease as the alkyl chain length of the pyridiniumIls increase. All the materials obtained exhibit Type II isotherm which represent non-porous materials. Low BET surface area and pore volume indicate that the materials were non-porous which is agreeable to the TEM images that show the presence of non-porous silica layer.

\section{ACKNOWLEDGEMENTS}

The authors gratefully acknowledge the NanoMITe (Health, Wellness and Medical research cluster - 5526306) and Putra Grant IPS project GP-IPS/2016/9472600

\section{REFERENCES}

[1] Johansson E M. Controlling the pore size and morphology of mesoporous silica. Sweden: Linkoping University, 2010

[2] Zhang J, Ma Y, Shi F, Liu L, Deng Y. Room temperature ionic liquids as templates in the synthesis of mesoporous silica via a sol-gel method. Microporous and Mesoporous Materials, 2009, 119(1):97-103

[3] Li Z, Yu L, Zheng L, Li N, Han S, Li G. Characterization studies on the ionic liquid-templated mesoporous silica with wormlike pores.Journal of Dispersion Science and Technology, 2008,29(7):1029-1034

[4] Chiang YD, Lian HY, Leo SY, Wang SG, Yamauchi Y, Wu KC. Controlling particle size and structural properties of mesoporous silica nanoparticles using the Taguchi method. Journal of Physical Chemistry C, 2011, 115(27):13158-13165

[5] Lv X, Zhang L, Xing F, Lin H. Controlled synthesis of monodispersed mesoporous silica nanoparticles: Particle size tuning and formation mechanism investigation. Microporous and Mesoporous Materials, 2016, 225, 238-244

[6] Li Z, Yu L, Dong B, Geng F, Zheng L, Li G. Synthesis and characterization of mesoporous silica templated by amphiphilic RTILs. Journal of Dispersion Science and Technology, 2008, 29(8):1066-1071 
[7] Wasserscheid P., Welton T. Ionic liquids in synthesis.Weinheim: Wiley-VCH Verlag GmBH and Co.,2007

[8] Zhou Y, Schattka J H, Antonietti M. Room-temperature ionic liquids as template to monolithic mesoporous silica with wormlike pores via a sol-gel nanocasting technique. Nano Letters, 2004,4(3):477-481

[9] Li X, Ma J, Wang J. Cytotoxicity, oxidative stress, and apoptosis in HepG2 cells induced by ionic liquid 1-methyl-3-octylimidazolium bromide. Ecotoxicology and Environmental Safety, 2015,120:342-348

[10]Jaitely V, Karatas A, Florence AT. Water-immiscible room temperature ionic liquids (RTILs) as drug reservoirs for controlled release. International Journal of Pharmaceutics, 2008,354(1):168-173

[11] Wang T, Kaper H, Antonietti M, Smarsly B. Templating behavior of a long-chain ionic liquid in the hydrothermal synthesis of mesoporous silica. Langmuir: The ACS Journal of Surfaces and Colloids, 2007,23(3):1489-1495

[12] Zhou Y, Antonietti M. A series of highly ordered, super-microporous, lamellar silicas prepared by nanocasting with ionic liquids. Chemistry of Materials, 2004,16(3):544-550

[13] Marek J, Stodulka P, Cabal J, Soukup O, Pohanka M, Korabecny J, Musilek K, Kuca K. Preparation of the pyridinium salts differing in the length of the N-alkyl substituent. Molecules, 2010,15(3):1967-1972

[14]Harjani JR, Singer RD, Garcia MT, Scammells PJ. Biodegradable pyridinium ionic liquids: Design, synthesis and evaluation. Green Chemistry, 2009, 11(1):83-90

[15] Yu M, Zhou L, Zhang J, Yuan P, Thorn P, Gu W, Yu C.A simple approach to prepare monodisperse mesoporous silica nanospheres with adjustable sizes. Journal of Colloid and Interface Science, 2012, 376(1):67-75

[16] Fu W H, Guan Y, Wang Y M, He MY. A facile synthesis of monodispersed mesoporous silica nanospheres with $\mathrm{Pm} 3 \mathrm{n}$ structure. Microporous and Mesoporous Materials, 2016,220:168-174

[17] Ward AJ, Pujari AA, Costanzo L, Masters AF, Maschmeyer T. Ionic liquid-templated preparation of mesoporous silica embedded with nanocrystalline sulfated zirconia. Nanoscale Research Letters, 2011,6(1):1-8 
[18] Chen Q, Han L, Gao C, Che S. Synthesis of monodispersed mesoporous silica spheres (MMSSs) with controlled particle size using gemini surfactant. Microporous and Mesoporous Materials, 2010,128(1):203-212

[19] Yamada H, Urata C, Higashitamori S, Aoyama Y, Yamauchi Y, Kuroda K. Critical roles of cationic surfactants in the preparation of colloidal mesostructured silica nanoparticles: Control of mesostructure, particle size, and dispersion. ACS Applied Materials and Interfaces, 2014,6(5):3491-3500

[20] Yu YJ, Xing JL, Pang JL, Jiang SH, Lam KF, Yang TQ, Xue QS, Zhang K, Wu P. Facile synthesis of size controllable dendritic mesoporous silica nanoparticles. ACS Applied Materials and Interfaces, 2014,6(24):22655-22665

[21] Alothman Z A. A review: Fundamental aspects of silicate mesoporous materials. Materials, 2012,5(12):2874-2902

\section{How to cite this article:}

Isa E.D.M., Rahman M.B.A., and Ahmad H.Silica coated ionic liquid templatedmesoporous silica nanoparticles. J. Fundam. Appl. Sci., 2017, 9(6S), 204-213. 